\section{Commentary: Please don't freeze my brain, perfuse it}

Jean Bachet, MD, FEBCTS

In their article titled "Comparison of dynamic brain metabolism during antegrade cerebral perfusion versus deep hypothermic circulatory arrest using proton magnetic resonance spectroscopy," Hanley and coworkers ${ }^{1}$ clearly demonstrate, through a fine experimental analysis of the evolution of a large number of neural brain metabolites in piglets, the safer and more efficacious use of antegrade cerebral perfusion (ACP) compared with deep hypothermic circulatory arrest (DHCA). This study confirms scientifically what has been largely observed clinically in surgeries requiring circulatory arrest, such as total aortic arch replacement, since the reintroduction of ACP by Guilmet and coworkers ${ }^{2,3}$ in France and Kazui and colleagues ${ }^{4}$ in Japan in the late 1980s and early 1990s.

In this regard, this article is quite interesting. Yet, some points merit discussion. First, the number of animals was very limited (3 piglets in the DHCA group and 2 in the ACP group). One may wonder whether a larger number of animals would demonstrate somewhat different results and, possibly, a less important difference between the 2 techniques. Similarly, one may wonder whether the use of piglets (very young animals, in which the development of the brain activity and metabolism is very important) could have exaggerated the difference between the 2 groups, and that the use of adult animals might have shown less dramatic differences.

In 2012, I published an editorial commentary titled "Are children young adults?" about an experimental study comparing, in piglets, 3 different ACP flows: physiological, reduced to $50 \%$, and extensive hypoperfusion. ${ }^{5}$ The authors of the study concluded that "selective cerebral perfusion using a moderate SCP flow regime

\footnotetext{
From the ADETEC, Suresnes, France

Disclosures: Author has nothing to disclose with regard to commercial support.

Received for publication Oct 30, 2019; accepted for publication Oct 30, 2019; available ahead of print Nov 22, 2019.

Address for reprints: Jean Bachet, MD, FEBCTS, ADETEC, 1, Place Marcel Legras, 92150 Suresnes, France (E-mail: assocadetec@aol.com).

J Thorac Cardiovasc Surg 2020;160:e231-2

$0022-5223 / \$ 36.00$

Copyright (C) 2019 by The American Association for Thoracic Surgery

https://doi.org/10.1016/j.jtcvs.2019.10.192
}

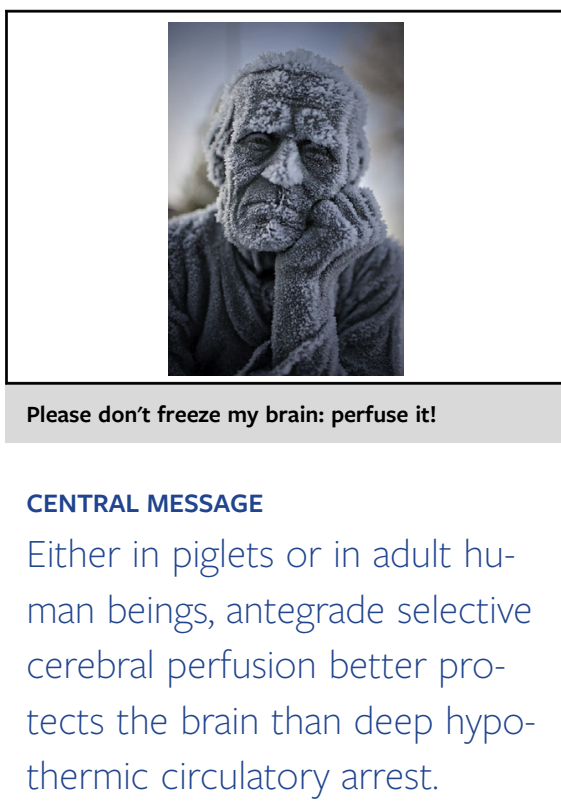

demonstrates comparable results to normal brain perfusion." 6 In my commentary, I raised the question of whether experimental observations in piglets could actually predict what could happen in human adults. Indeed, in present surgical practice, most procedures implying the use of some method of cerebral protection are performed in adults. Because of the compliance, adaptability, and maturity of the adult brain, various temperature levels are tolerated rather well, and the clinical results have been quite satisfactory so far.

In addition, as I wrote, "by definition, neuropsychological testing is practically impossible in any animal model. Contrary to babies and infants, piglets have no development of any superior cognitive activity, and it is quite impossible to assess, through immediate histological and chemical changes only, the impairment or maintenance of the normal acquisition of speech, intelligence, memory, emotions, etc. and all those features that make a difference between limited and bright individuals. Most signs of impairment of those cognitive functions become obvious, through behaviour or learning problems at home or at school, after a long period of time (sometimes years) following the intraoperative insult." 5

The long duration of the circulatory arrest used in the present study also might have introduced some bias. In clinical practice and through the vast literature on cerebral protection, the mean duration of total circulatory arrest with or without cerebral perfusion is generally between 30 and 45 minutes. Perhaps restricting the time of the circulatory 
arrest with or without ACP to those limits could have resulted in a smaller difference.

Last, but not least, most clinical ACP procedures are performed not using deep hypothermia, but rather at a perfusate and core moderate hypothermia (generally between $23^{\circ} \mathrm{C}$ and $28^{\circ} \mathrm{C}$ ). Could the introduction of this factor in the experimental study enhance the advantage of ACP over DHCA and definitively demonstrate the superiority and larger safety of this technique?

Without a doubt, the study by Hanley and coworkers is quite contributory. However, the same study carried out in a larger number of adult animals perhaps could be even more demonstrative and provide definite unquestionable proof of the superiority of $\mathrm{ACP}$ over DHCA.

\section{References}

1. Hanley FL, Ito H, Gu M, Hurd R, Riemer RK, Spielman D. Comparison of dynamic brain metabolism during antegrade cerebral perfusion versus deep hypothermic circulatory arrest using proton magnetic resonance spectroscopy. J Thorac Cardiovasc Surg. 2020;160:e225-7.

2. Guilmet D, Roux PM, Bachet J, Goudot B, Tawil N, Diaz F. [A new technique of cerebral protection: surgery of the aortic arch]. Presse Med. 1986;15:1096-8 [in French].

3. Bachet J, Guilmet D, Goudot B, Termignon JL, Teodori G, Dreyfus G, et al. Cold cerebroplegia. A new technique of cerebral protection during operations on the transverse aortic arch. J Thorac Cardiovasc Surg. 1991;102:85-93 [discussion: 93-4].

4. Kazui T, Inoue N, Yamada O, Komatsu S. Selective cerebral perfusion during operation for aneurysms of the aortic arch: a reassessment. Ann Thorac Surg. 1992;53:109-14.

5. Bachet J. Re: selective cerebral perfusion using moderate flow in complex cardiac surgery provides sufficient neuroprotection. Are children young adults? Eur J Cardiothorac Surg. 2012;42:710-1.

6. Emrich F, Walther T, Muth P, Ullmann C, Rastan AJ, Dhein S, et al. Selective cerebral perfusion using moderate flow in complex cardiac surgery provides sufficient neuroprotection. Eur J Cardiothorac Surg. 2012;42:704-10. 